\title{
Inequalities in health in The Netherlands according to age, gender, marital status, level of education, degree of urbanization, and region
}

\author{
J.P. MACKENBACH *
}

\begin{abstract}
Inequalities in health have attracted much epidemiological interest. Usually, differences in rates of ill-health between the sexes, among socioeconomic groups, geographical reglons, etc., are quantified separately, so that it remains unclear which variables are assodated with the largest degree of variation. We analyzed variations in percelved general health, prevalence of chronic conditions, and mortality associated with six sociodemographic characteristics: age, gender, marttal status, level of education, degree of urbanization and reglon. Nationally representatlve data from the Netherlands were used. The Index of Dissimilarity (the proportion of the number of cases of ill-health in the whole population which has to be redistributed to achieve complete equality) was used to summarize the degree of variation in these health measures. Age was associated with the highest degree of variation in all three health measures. The rank order of the other background characteristics differed slightly among health measures, but on the whole gender, marital status and level of education appeared to be of equal importance. Degree of urbanization and region were less important, although not negliglble. Improvements in the health status of groups having high rates of health problems could contribute substantially to further reduction of the burden of IIt-health in the population as a whole. The results of this analysis suggest that such interventions should not be limited to one dimension of inequality only, and that, at least in the Netherlands, inequalities by gender, marital status and level of education deserve equal attention from health policy makers. Examples of spectfic factors and mechanisms involved in these inequalities are given, and possible strategies for reduction of these inequalitles are discussed.
\end{abstract}

Key words: inequalities, sociodemographic characteristics, perceived general health, chronic conditions, mortality

$\mathrm{V}$

ariation in rates of ill-health among population subgroups is a frequently researched topic in epidemiology. The study of such variation may serve two purposes. On the one hand, analyses of the variation in the frequency of health problems may lead to hypotheses concerning the causes of these problems (Hennekens \& Buring 1987). This is exemplified by epidemiological studies concerned with geographical variation in morbidity or mortality rates. On the other hand, analyses of variation in the frequency of health problems may also help target subgroups of the population in need of more than the usual amount of preventive or curative health service interventions (Florey 1983). Inequalities in health among socioeconomic groups are frequently viewed from this perspective, as illustrated by the World Health Organization's call for a reduction of such inequalities by 25\% between 1985 and the year 2000 (World Health Organization 1985). Both purposes are obviously interrelated, because a reduction of the health burden of disadvantaged groups requires knowledge of the causes of these health problems. At the same time, a systematic study of vulnerable groups is likely to generate ideas on the etiology of health problems in the population at large.

- Correspondence Prof. dr L.P. Mackenbuch, Department of Publik Health Social Medldne, Erasmus University Rotterdam, P.O. Box 1738 ,
Most epidemiological studies of variation in rates of illhealth among population subgroups take a one-sided view of such inequalities, in the sense that these are studied along one 'axis' only: region, or socio-economic status, or another background characteristic. This may be appropriate when the purpose is to generate hypotheses on the etiology of health problems (provided that the factors omitted in the analysis are not confounding the relationship under study). However, when the purpose is to help policy makers to identify subgroups in need of special attention, a more comprehensive approach would help enormously in setting priorities. Only a comprehensive approach will tell which of the 'axes' is associated with the largest amount of variation in the frequency of health problems. The purpose of this paper is to compare the degree of variation in rates of ill-health associated with six different sociodemographic characteristics in the Netherlands: age, gender, marital status, level of education, degree of urbanization, and region. Most of these background characteristics will influence health only 'indirectly' through more specific intermediary factors and mechanisms (e.g. smoking, psychosocial stress, occupational exposures). In the case of gender, and especially age, 'direct' biological mechanisms are also involved. Although it would have been interesting to include even more factors in the analysis, such as ethnicity or religious affiliation, availability of data for these other factors was insufficient. 


\section{MATERIALS AND METHODS}

Three indicators of ill-health were selected: perceived general health (percentage reporting their general health as being less than 'good'), the preualence of chronic conditions (number of reported chronic conditions per 100 persons), and all-cause mortality (rates per 100,000 person-years).

Data on perceived general health and chronic conditions were available from the Netherlands Health Interview Survey. This is a continuous survey by the Netherlands Central Bureau of Statistics which started in 1981 and involves a nationally representative sample of approximately 10,000 non-institutionalized persons each year. The prevalence of chronic conditions is measured by showing responders a list with 26 named conditions, and asking them to state for each of these whether they have had it during the past 12 months or not. The survey also contains questions concerning age, gender, marital status, level of education, and place of residence. The design of these comparisons is cross-sectional.

Data on mortality were available from the national mortality register of the Netherlands Central Bureau of Statistics. This is derived from the municipal population registers, which record births, deaths, changes of marital status, and changes of address. These population registers are virtually complete and are kept up-to-date continuously. The mortality register also contains information on age, gender, marital status, and place of residence of the deceased.

Level of education is not recorded in the mortality register. The data presented here on mortality experience by level of education were taken from a study of a complete birth cohort of 78,505 18-year old men screened for military service in 1950 and followed up until 1982 (Doombos \& Kromhout 1990). Three thousand fifty-six of these men died during follow-up. The mortality experience of this cohort is restricted to the 1970s and early 1980 s. This study is thought to give the best available estimate of current mortality differences by level of education (among men) in the Netherlands (Kunst et al. 1990). All data apply to the first half of the 1980 s. Several years' data were combined in order to reduce random error.

Rates in different subgroups of the population are presented in an age- and sex-standardized form, using the total Netherlands population as the standard. Standardization is necessary when different population subgroups have different age- and sex-structures, which is frequently the case and would lead to seriously biased estimates of differences in rates of ill-health. In most instances, data were published in an age- and sex-standardized form and used as presented. Additional adjustments for each of the other sociodemographic characteristics (e.g. when studying level of education, adjustments for marital status, region, degree of urbanization, in addition to age and sex), were not feasible due to lack of sufficiently detailed data.

For each of the six sociodemographic characteristics, the degree of variation in the three measures of ill-health was quantified in two steps. The first consisted of the calculation of a simple ratio between each of the (standardized) rates in the subgroups and the average rate in the Dutch population as a whole. These Rate Ratios (RR) describe the pattern and extent of the variation in rates among subgroups, while bringing every health indicator on the same scale with average value $=1.00$. Rate Ratios were preferred to the more conventional Relative Risk measure because the latter requires the identification of a reference category of unexposed. For most sociodemographic characteristics such a reference category is not obvious. Choosing the subgroup with the lowest rates would lead to different reference categories for different health indicators. We therefore preferred to take the whole population as 'reference category'.

A summary measure of the degree of variation in rates of ill-health was then calculated. A measure was selected which uses information on all subgroups (not only on the extreme ones, as in range measures) and which weighs the deviation in each of the subgroups with its population share (so that a high rate of ill-health in a small segment of the total population receives less weight than an equally high rate in a larger subgroup).

In principle, the Population-Attributable Risk or Etiological Fraction (Kleinbaum et al. 1982) fulfils these criteria, but this measure like the Relative Risk requires the designation of a category of unexposed. As was stated above, this is impossible here. We therefore chose a less well-known measure, the Index of Dissimilarity (ID) (Preston et al. 1985, Koskinen 1985, Wagstaffet al. 1991), which does fulfil the two criteria but does not require the designation of a non-exposed category. It is instead derived from the Rate Ratio measure given above:

$I D=\frac{\sum_{i=1}^{k} p_{i} *\left|R R_{i}-1\right|}{2}$

in which

ID = Index of Dissimilarity

$\mathrm{i}$ = socio-demographic subgroup (age-group $1, \ldots, \mathrm{k}$; region $1, \ldots, k$; etc.)

$\mathrm{p}_{i}=$ proportion of population in socio-demographic subgroup $i$

$\mathrm{RR}_{\mathbf{1}}$ = Rate Ratio of socio-demographic subgroup $\mathrm{i}$.

The calculation of the Index of Dissimilarity involves taking a weighted average of the deviations from the national average in each sociodemographic subgroup. These deyiations are equal to the absolute value of the Rate Ratio minus unity. This weighted average is divided by two to arrive at a very straightforward interpretation: the Index of Dissimilarity equals the proportion of the number of cases of ill-health in the whole population which has to be redistributed between sociodemographic subgroups in order to give each of them the same Rate Ratio (RR=1.00).

\section{RESULTS}

The results of the first step of the analysis (calculation of Rate Ratios for each of the health indicators and population subgroups) are presented in table 1 and 2. As ex- 
pected, ageing was associated with an increasing percentage of the population rating its health as less than 'good', an increasing prevalence of chronic conditions, as well as increasing mortality (table 1 ). The increase, however, is much more dramatic for mortality rates than for the two health interview survey-based measures. This may, in part, be due to the exclusion of institutionalized persons in the sample for this survey, but the pattern is already

Table 1 Vanation in rates of ill-healch by age, gender, marital status, and level of educarion

\begin{tabular}{|c|c|c|c|c|}
\hline & \multirow[t]{2}{*}{$\begin{array}{l}\text { Proportion of total } \\
\text { population }\end{array}$} & \multicolumn{3}{|c|}{ Rate Ratio } \\
\hline & & $\begin{array}{l}\text { Percentage rating health as } \\
\text { less than 'good' } 1981-1985^{b}\end{array}$ & $\begin{array}{l}\text { Chronic conditions per } \\
100 \text { persons } 1981-1985^{b}\end{array}$ & $\begin{array}{c}\text { Mortality rate per } 10^{5} \\
\text { person-years } 1984\end{array}$ \\
\hline \multicolumn{5}{|l|}{$\overline{\text { Age }}$} \\
\hline $0 \rightarrow 4$ & 0.06 & $0.48^{c}$ & $0.30^{6}$ & 0.24 \\
\hline $5-9$ & 0.06 & $0.06^{c}$ & $0.34^{\mathrm{c}}$ & 0.03 \\
\hline $10-14$ & 0.08 & $0.29^{c}$ & $0.33^{c}$ & 0.03 \\
\hline $15-19$ & 0.08 & 0.37 & 0.41 & 0.05 \\
\hline $20-24$ & 0.09 & 0.46 & 0.50 & 0.06 \\
\hline $25-29$ & 0.08 & 0.52 & 0.65 & 0.07 \\
\hline $30-34$ & 0.08 & 0.69 & 0.81 & 0.09 \\
\hline $35-39$ & 0.08 & 0.78 & 0.92 & 0.13 \\
\hline $40-44$ & 0.06 & 0.98 & 1.08 & 0.20 \\
\hline $45-49$ & 0.06 & 1.35 & 1.28 & 0.34 \\
\hline $50-54$ & 0.05 & 1.73 & 1.72 & 0.59 \\
\hline $55-59$ & 0.05 & 1.93 & 1.84 & 0.98 \\
\hline $60-64$ & 0.05 & 2.12 & 2.08 & 1.61 \\
\hline $65-69$ & 0.04 & 2.10 & 2.12 & 2.57 \\
\hline $70-74$ & 0.03 & 2.25 & 2.19 & 4.13 \\
\hline $75-79$ & 0.02 & 2.65 & 2.29 & 6.67 \\
\hline $80-84$ & 0.02 & 2.37 & 2.10 & 10.85 \\
\hline $85+$ & 0.01 & 2.44 & 2.32 & 20.93 \\
\hline Total & 1.00 & 1.00 & 1.00 & 1.00 \\
\hline \multicolumn{5}{|l|}{ Gender } \\
\hline Men & 0.49 & 0.94 & 0.90 & 1.31 \\
\hline Women & 0.51 & 1.06 & 1.07 & 0.71 \\
\hline Total & 1.00 & 1.00 & 1.00 & 1.00 \\
\hline \multicolumn{5}{|l|}{ Marital status ${ }^{d}$} \\
\hline Never married & 0.30 & 0.98 & 0.93 & 1.41 \\
\hline Married & 0.59 & 0.98 & 1.02 & 0.89 \\
\hline Widowed & 0.07 & 0.94 & 0.83 & 1.81 \\
\hline Divorced & 0.04 & 1.65 & 1.46 & 1.34 \\
\hline Total & 1.00 & $1 . \infty 0$ & 1.00 & 1.00 \\
\hline \multicolumn{5}{|l|}{ Level of education ${ }^{e}$} \\
\hline Primary school ${ }^{f}$ & 0.27 & 1.41 & 1.12 & 1.14 \\
\hline $\begin{array}{l}\text { Lower secondary } \\
\text { educarion }\end{array}$ & 0.32 & 0.98 & 1.00 & 0.93 \\
\hline Secondary education & 0.30 & 0.81 & 0.95 & 0.98 \\
\hline Vocational colleges & 0.09 & 0.62 & 0.85 & \\
\hline University & 0.03 & 0.64 & 0.71 & 0.77 \\
\hline Total & 1.00 & 1.00 & 1.00 & 1.00 \\
\hline
\end{tabular}

- Seandardized for age and sex, except in the case of gender (sandardized for age onty) and age (no standardization at all).

${ }^{b}$ Mostly resuicted to population 216 years of ase.

${ }^{c}$ Besed on proxy intervieoss with parents

Rexricied to poputation 216 yeans or 220 years.

e The mortality data are based on a 32-year follow-up of a complete cohor of men 18 years old in 1950 . In thus cohort the distribution across levels

of education was different from that listed in the first column. The population shares are primary school $48 \%$, lower seconthry education $21 \%$,

secondary education 18\%, and vocauonal colleges/univeraty $13 \%$

Ends at ape 12 in the Necherlands.

Sorrces: Age Centraal Bureau voor de Statisuek 1988, 1986a. Gender. Central Bureau voor de Statisnek 1988, 1986a. Mantral satus: Centraal Bureau

voor de Statistiek 1988, 1986a. Level of education: Centraal Bureau voor de Statistiek 1988, Doombos \& Kromhout 1990. 
evident at ages (i.e. below 80) where the institutionalized represent only a minor proportion of the total population. Another explanation could be that the increase with age is much more pronounced for potentially fatal diseases than for other health problems, and/or that the increase with age of mortality rates reflects both increasing incidence or prevalence rates and increasing case fatality. Another difference between the three patterns is observed in the younger age-groups. For the percentage rating health as less than 'good', and for mortality, the most favourable figures are not found in the youngest age-group but at slightly older ages (10-14, and 5-14, respectively). For the prevalence of chronic conditions such a pattern is not evident.

Greater differences in patterns among the three health indicators are seen in the case of variation between the sexes (table 1). The percentage rating health as less than 'good' as well as the prevalence of chronic conditions are higher in women, whereas mortality rates are higher in men. This may partly reflect differences in reporting of health problems between men and women, but may also be due to a higher prevalence of non-fatal conditions among women, and of fatal conditions among men.

Patterns of variation by marital status also differ between health indicators (table 1). Unfavourable figures for all three indicators are found among divorced persons. Married persons, on the other hand, have low mortality rates and average rates for the two health interview survey- based measures. Never married and widowed persons have high mortality rates but low to average rates for percentage rating health as less than 'good' and prevalence of chronic conditions.

More consistent patterns are seen for level of education (table 1) and degree of urbanization (table 2). Persons with a higher level of education in general have a better perceived health, a lower prevalence of chronic conditions, and lower mortality rates. The differences are largest for perceived health. There is a similarly regular gradient for degree of urbanization: the more rural a municipality, the more favourable the rates of ill-health, irrespective of the indicator chosen.

Regional variation in rates of ill-health again shows diverging patterns for the three indicators (table 2). For example, Zeeland is characterized by low mortality rates but a high precentage of the population rating its health as less than 'good'. The range of variation on the whole is rather small: although 11 different subgroups are distinguished, the Rate Ratios range between 0.85 and 1.15 (perceived health), 0.94 and 1.22 (chronic conditions) and 0.89 and 1.08 (mortality).

Table 3 presents the results of the second and final step of the analysis (calculation of the summary measure, i.e. the Index of Dissimilarity). This enables us to compare the extent of variation in rates of ill-health between sociodemographic characteristics. For all three indicators, age is associated with the largest degree of variation. Removal

Table 2 Variation in rates of 11 -health by degree of urbanization and region

\begin{tabular}{|c|c|c|c|c|}
\hline & \multirow[t]{2}{*}{$\begin{array}{l}\text { Proportion of total } \\
\text { population }\end{array}$} & \multicolumn{3}{|c|}{ Rate Ratio" } \\
\hline & & $\begin{array}{l}\text { Percentage rating health as } \\
\text { less than 'good' } 1981.1985^{\text {b }}\end{array}$ & $\begin{array}{l}\text { Chronic conditions per } \\
100 \text { persons } 1981-1985^{b}\end{array}$ & $\begin{array}{c}\text { Mortality rate per } 10^{5} \\
\text { person-years } 1985\end{array}$ \\
\hline \multicolumn{5}{|l|}{ Degree of urbanization } \\
\hline Rural municipalitıes & 0.12 & 0.89 & 0.91 & 0.90 \\
\hline $\begin{array}{l}\text { Urbanıed rural } \\
\text { municipalities }\end{array}$ & 0.37 & 0.93 & 0.93 & 0.98 \\
\hline $\begin{array}{l}\text { Small and } \\
\text { medium-sized towns }\end{array}$ & 0.26 & 1.05 & 1.06 & 1.02 \\
\hline Large towns & 0.25 & 1.11 & 1.06 & 1.05 \\
\hline Total & 1.00 & 1.00 & 1.00 & 1.00 \\
\hline \multicolumn{5}{|l|}{ Region } \\
\hline Groningen & 0.04 & 0.94 & $1 . \infty$ & 1.01 \\
\hline Friesland & 0.04 & 0.85 & 1.00 & 0.95 \\
\hline Drenthe & 0.03 & 1.01 & 1.00 & 0.99 \\
\hline Overijssel & 0.07 & 1.04 & 0.97 & 1.04 \\
\hline Gelderland & 0.12 & $0.94^{c}$ & $1 . \infty$ & 1.01 \\
\hline Utrecht & 0.06 & 1.03 & 1.22 & 0.96 \\
\hline Noord-Holland & 0.16 & 1.03 & 1.09 & 0.99 \\
\hline Zuid.Holland & 0.22 & 0.99 & 0.94 & 0.99 \\
\hline Zeeland & 0.02 & 1.10 & 1.00 & 0.89 \\
\hline Noord-Brabant & 0.15 & 0.94 & 0.94 & 1.02 \\
\hline Limburg & 0.08 & 1.15 & $1 . \infty$ & 1.08 \\
\hline Total $^{d}$ & 1.00 & 1.00 & $1 . \infty$ & 1.00 \\
\hline
\end{tabular}

Standardized for age and sex

${ }^{b}$ Resriced to population $\geq 16$ years

cIncluding Zuidelijke IJsselmeer Polders

Incluting Zuidelije IIsselmeer Polders and Central Person Regiorn.

Sources: Degree of urbanizarion: Centraal Bureau voos de Starisuek 1982, Sonsbeck 1987 Region: Centrad Bureau voor de Starisdick 1987, Sonsbeck 1987. 
Table 3 Degree of variation in rates of 1 ll-health by 6 different socio-demographic characterstics

\begin{tabular}{|c|c|c|c|}
\hline \multirow[t]{2}{*}{$\begin{array}{l}\text { Sociodemographic } \\
\text { characteristic }\end{array}$} & \multicolumn{3}{|c|}{ Index of Dissimilanty } \\
\hline & $\begin{array}{l}\text { Percentage rating } \\
\text { health as less than 'good' }\end{array}$ & $\begin{array}{l}\text { Chronic conditions } \\
\text { per } 100 \text { persons }\end{array}$ & $\begin{array}{l}\text { Mortality rate per } \\
10^{5} \text { person-years }\end{array}$ \\
\hline Age & 0.309 & 0.286 & 0.682 \\
\hline Gender & 0.030 & 0.042 & 0.150 \\
\hline Marital status & 0.024 & 0.032 & 0.129 \\
\hline Level of education & 0.110 & 0.035 & 0.066 \\
\hline Degree of urbanization & 0.040 & 0.034 & 0.019 \\
\hline Region & 0.025 & 0.026 & 0.012 \\
\hline
\end{tabular}

of the variation in rates of ill-health by age would require substantial redistributions involving $31 \%$ of all cases of less-than-'good' perceived general health, $29 \%$ of all cases of chronic conditions, and $68 \%$ of all deaths.

For perceived general health, level of education is the next most important characteristic. Its Index of Dissimilarity $(0.110)$ is about one third of that for age $(0.309)$ and about three to four times that for the other four characteristics (ranging from 0.024 to 0.040 ).

For the prevalence of chronic conditions there is not much difference between sociodemographic characteristics (other than age) in the associated degree of variation: the Index of Dissimilarity ranges from 0.026 (region) to 0.042 (gender).

For mortality, on the other hand, differences between sociodemographic characteristics are extremely large. Not only is the largest value of the Index of Dissimilarity ( 0.682 for age) larger than the largest value observed with each of the other two indicators, but the smallest value ( 0.012 for region) also is smaller than any other Index of Dissimilarity in table 3. After age, gender is the most important variable associated with inequalities in mortality, closely followed by marital status. Level of education occupies an intermediate position.

\section{DISCUSSION}

The Dutch population (and, for that matter, any other national population) is heterogeneous with respect to the frequency of occurrence of health problems. We quantified the degree of variation in frequency of health problems associated with six different sociodemographic characteristics. Not surprisingly, age is associated with the highest degree of variation in all three health measures employed. The rank order of the other characteristics differs among the health measures, but on the whole gender, marital status and level of education appear to be equally important, and to be more important in that respect than degree of urbanization and region.

We used the Index of Dissimilarity to quantify the degree of variation in frequency of health problems. This measure weighs the deviation from the national average in each of the subgroups with its popularion share, and thus is more sensitive to deviations if they occur in larger subgroups. For health policy purposes this would seem to be a plausible procedure, and to be preferable to procedures which

do not take this into account.
It is important to note, however, that the Index of Dissimilarity does not take into account the direction of the differences. For example, in the case of gender, the Index of Dissimilarity does not disclose that for the percentage rating health as less than 'good' and chronic conditions per 100 persons, men are better off than women, while for mortality rates the reverse is true. Another sociodemographic characteristic where differences in ranking between subgroups remain concealed is marital status. It would be interesting to calculate a measure of inequality for a health indicator which combines morbidity and mortality, such as diseasefree life expectancy (Robine et al. 1987, Ginneken et al. 1991). We expect that with such an indicator level of education would appear as a more important variable associated with inequality than gender and marital status. We do not know to what extent our results may be generalized to other industrialized countries. We are not aware of any other attempt to compare in a quantitative way the degree of variation in ill-health associated with a set of different sociodemographic characteristics. We do know, however, that the degree of variation in ill-health between socioeconomic groups probably differs between countries (Leclerc et al. 1990, Valkonen 1989, Vågerö \& Lundberg 1989). It is therefore quite possible that the ranking of sociodemographic characteristics according to the associated degree of variation in health also differs between countries. We would welcome attempts to replicate this analysis on data from other countries.

The results of our analysis suggest that health policy should not exclusively focus on one dimension of inequality only, and that, at least in the Netherlands, inequalities by gender, marital status and level of education deserve equal amounts of attention. But what to do about these inequalities in health? The most straightforward way to eliminate these inequalities would be to reduce the variation in the sociodemographic characteristics as such. This is, however, completely impossible in the case of gender and marital status, and only partly possible in the case of level of education. In the latter case, the removal of barriers to educational achievement for children from the lower socioeconomic classes would seem to be a good and realistic example of a strategy aiming at reducing the variation in sociodemographic characteristics as such. Unfortunately, such examples are rare, and the only remaining way to reduce variation in health associated with these characteristics is to search for more specific intermediary factors and mechanisms through which these characteristics 'indirectly' influence health.

Although a review of these specific factors and mechanisms is outside the scope of this paper, it will be attempted to make a number of general remarks on the basis of the available literature and specific information from the 
Netherlands. First of all, it is necessary to distingursh between the contribution of selection processes (in which ill-health determines the membership of a sociodemographic group) and that of 'causal' effects of sociodemographic characteristics on health (through the differential distribution of specific causes of ill-health). Selection processes cannot operate in the case of gender, but they can in the case of marital status (where ill-health may prevent marriage or lead to a divorce) and level of education (where ill-health may have hampered school careers). Although there is some evidence for these selection processes both in the case of mantal status and in the case of level of education (or socioeconomic status in general), the contribution of these processes to the explanation of inequalities in ill-health is generally considered to be small (Morgan 1980, Wilkinson 1986).

This leaves us with the differential distribution of causes of ill-health, and with the question which of these 'intermediary' factors contributes most to the explanation of inequalities in health. In the case of gender, genetic factors have to be considered, the distribution of which is clearly not subject to health policy measures. On the other hand, even in the case of gender the effects of these genetic factors vary tremendously depending on environmental conditions, as is evident from trends over time of sex differentials in mortality (Waldron 1983). Reviews of factors involved in inequalities in health by gender (MacIntyre 1986, Ruzicka \& Lopez 1983), marital status (MacIntyre 1986, Morgan 1980) and socioeconomic status (Marmot et al. 1987) suggest that the following groups of (non-genetic) factors probably always contribute to a varying extent:

- aspects of behaviour (smoking, alcohol consumption, diet);

- material life circumstances (level of living, housing, occupational and other exposures);

- psychosocial stress-related circumstances (life events, social support);

- health care (adequate supply and use of preventive and curative services).

Many of these factors may be subject to health policy interventions, but it is of course dependent on the quantitative contribution of a factor to the explanation of a pattern of ill-health how much effort one would like to spend on it.

Recognizing this, and acknowledging the substantial public health impact of socioeconomic inequalities in health, the Netherlands' Ministry of Welfare, Public Health and Cultural Affairs recently decided to launch a national research programme in the area of socio-economic inequalities in health (Mackenbach 1991). Although the programme contains descriptive, explanatory and intervention-oriented studies, the focus is on explanatory studies. The main purpose of these explanatory studies is to determine the contribution of the factors mentioned above to the generation of socio-economic inequalities in health. Preliminary results of this programme, which covers the five years between 1989 and 1993, show that the following factors are more prevalent in lower socio- economic groups: smoking and obesity ('aspects of behaviour'); unfavourable physical working conditions ('material life circumstances'); lack of social support ('psychosocial stress-related factors'); and low use of preventive health care services ('health care') (Mackenbach 1992). Clearly, for some of these factors health policy measures could be considered. Recently a conference has been held to gain political and societal support for a strategy to reduce socio-economic inequalities in health through measures aimed at these factors (Wetenschappelijke Raad voor het Regeringsbeleid 1991). This example from the Netherlands may serve to illustrate the possibilities for a systematic approach to the explanation and reduction of inequalities in health.

The author thanks Anton Kunst and Eddy van Doorslaer for a number of enlightening discussions on measures of inequality.

\section{REFERENCES}

Centraal Bureau voor de Statistiek (1982). Vademecum Gezondheidsstatistıek 1982. Den Haag: Staatsuitgeverij. Centraal Bureau voor de Statistiek (1986a). Compendium Gezondheidsstatistiek Nederland 1986. Den Haag: Staatsuitgeverij.

Centraal Bureau voor de Statistiek (1986b). Sterfte 1981-1985. Maandstatistiek Bevolking no volume (september): 17-23.

Centraal Bureau voor de Statistiek (1987). Regionaal Vademecum Gezondheidsstatistiek 1985. Den Haag: Staatsuitgeverij. Centraal Bureau voor de Statistuek (1988). Netherlands Health Interview Survey 1981-1985. Den Haag: Staatsuitgeverı.

Doombos G, Kromhout D (1990). Educational level and mortality in a 32-year follow-up study of 18 -year old men in the Netherlands. Int J Epidemiol 19: 374-9.

Florey C du V (1983). An introduction to community medicine. Edinburgh: Churchill Livingstone.

Ginneken JKS van, Dissevelt AG, Water HPA van de et al. (1991) Results of two methods to determine health expectancy in the Netherlands in 1981-1985 Soc Sci Med 32: 1129-36.

Hennekens $\mathrm{CH}$, Buring JE (1987). Epidemiology in medicine. Boston: Little Brown.

Kleinbaum DG, Kupper LL Morgenstern H (1982). Epidemiologic research. London: Lffetime Learning Publications.

Koskinen 5 (1985). Time trends in cause-specific mortality by occupational class in England and Wales. Paper presented at IUSSP 20th International Population Conference, 1985.

Kunst AE, Looman CWN, Mackenbach JP (1990). Sodo-economic mortality differences in the Netherlands in 1950-1984: a regional study of cause-specific mortality in the Netherlands. Soc Sci Med 31: 141-52.

Leclerc A, Lert F, Fabien C (1990). Differential mortality. some comparisons between England and Wales, Finland and France, based on inequality measures. Int J Epidemiol 19: $1001-10$.

Maclntyre $S$ (1986). The patterning of health by social position in contemporary Britain: directions for sociological research. Soc Sci Med 23: 393-415.

Mackenbach JP (ed.) (1991). Socio-conomic health differences; proceedings of a symposium held on February 1st, 1991 in Rotterdam, the Netherlands. Ministerie van Welzijn, Volksgezondheid en Cultuur, Rijswijk.

Mackenbach JP (1992). Socio-conomic health differences in the Netherlands: a review of recent empirical findings. Soc Sci Med 34: 213-26.

Marmot MG, Kogevinas M, Elston MA (1987). Socialeconomic status and disease. Ann Rev Publ Health 8: 111-35.

Morgan M (1980). Marital status, heatth, illness and service use. Soc Sci Med 14A: 633-43.

Preston SH, Haines MR, Pamuk E (1981). Effect of industrialization and urbanization on mortality in developed countries. In: Solicited Papers Vol. 2, IUSSP 19th International Population Conference. IUSSP, Liège. 
Robine JM, Brouard N, Colvez A (1987). Les indicateurs d'espérance de vie sans incapacite. Rev Epidemiol et Sante Publ 35: 206-24.

Ruzdcka LT, Lopez A (1983). Conclusions and prospects. In: Lopez A, Ruzicka LT. Sex differentials in mortality: trends, determinants and consequences. Canberra: Australian National University.

Sonsbeek JLA van (1987). Gezondheidsverschillen in regionaal perspectief. Maandberidht Gezondheid no volume (january). 5-11.

Văgero D, Lundberg $O$ (1989). Heafth inequalities in Britain and Sweden. Lancet 2: 35-6.

Valkonen T (1989). Adult mortality and level of education: a comparison of six countries. In: Fox $」$ (ed.). Health inequalities in European countries. Aldershot: Gower Publishing Company, pp.142-63.

Wagstaff A, Pad P, Doorslaer E van (1991). On the measurement of inequalities in health. Soc Sci Med 33: 545-57.
Waldron I (1983). The role of genetic and biological factors in sex differences in mortality. In: Lopez A, Ruzidka LT. Sex differentials in mortality trends, determinants and consequences. Canberra: Australian National University.

Wetenschappelijke Raad voor het Regeringsbeleid (1991) Sociaal-economische gezondheidsverschillen en beleid; pre-adviezen. 's-Gravenhage: SDU-uitgeverij.

Wilkinson RG (1986). Socio-economic differences in mortality interpreting the data on their size and trends. In: Wilkinson RG (ed.). Cass and health. London: Tavistock.

World Health Organization (1985). Targets for health for all. Copenhagen: WHO Regional Office for Europe.

Received 9 December 1991, accepted 6 March 1992 